\title{
Tyrosine Kinase-Associated Receptor Down-Regulation
}

National Cancer Institute

\section{Source}

National Cancer Institute. Tyrosine Kinase-Associated Receptor Down-Regulation. NCI

Thesaurus. Code C42789.

A multicellular process that regulates the number of tyrosine kinase-associated transmembrane receptors, by means of increased internalization or decreased expression of the transmembrane receptor. This process is involved in dampening the response to extracellular signals. 